ORIGINAL ARTICLE

\title{
Incidence of sports and recreation related injuries resulting in hospitalization in Wisconsin in 2000
}

\author{
R L Dempsey, P M Layde, P W Laud, C E Guse, S W Hargarten
}

Injury Prevention 2005;11:91-96. doi: 10.1136/ip.2004.006205

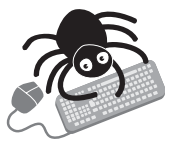

Table 4 can be viewed on our website.

See end of article for authors' affiliations

Correspondence to Dr R L Dempsey, Medical College of Wisconsin 8701 Watertown Plank Road, Milwaukee, WI 53226, USA; rdempsey@ mow.edu
Objective: To describe the incidence and patterns of sports and recreation related injuries resulting in inpatient hospitalization in Wisconsin. Although much sports and recreation related injury research has focused on the emergency department setting, little is known about the scope or characteristics of more severe sports injuries resulting in hospitalization.

Setting: The Wisconsin Bureau of Health Information (BHI) maintains hospital inpatient discharge data through a statewide mandatory reporting system. The database contains demographic and health information on all patients hospitalized in acute care non-federal hospitals in Wisconsin.

Methods: The authors developed a classification scheme based on the International Classification of Diseases External cause of injury code (E code) to identify hospitalizations for sports and recreation related injuries from the $\mathrm{BHI}$ data files (2000). Due to the uncertainty within E codes in specifying sports and recreation related injuries, the authors used Bayesian analysis to model the incidence of these types of injuries.

Results: There were 1714 (95\% credible interval 1499 to 2022) sports and recreation-related injury hospitalizations in Wisconsin in 2000 (32.0 per 100000 population). The most common mechanisms of injury were being struck by/against an object in sports (6.4 per 100000 population) and pedal cycle riding (6.2 per 100000$)$. Ten to 19 year olds had the highest rate of sports and recreation related injury hospitalization (65.3 per 100000 population), and males overall had a rate four times higher than females.

Conclusions: Over 1700 sports and recreation related injuries occurred in Wisconsin in 2000 that were treated during an inpatient hospitalization. Sports and recreation activities result in a substantial number of serious, as well as minor injuries. Prevention efforts aimed at reducing injuries while continuing to promote participation in physical activity for all ages are critical.
P romoting increased physical activity through participation in sporting and recreational activities is potentially a powerful tool for fighting the US and worldwide "obesity epidemic" and improving public health. ${ }^{1-3}$ However, participation in sports and recreational activities involves a risk for injury, and sports and recreation related injuries have a considerable public health impact. Over 4.2 million non-fatal sports and recreation related injuries were treated in US hospital emergency departments from July 2000 to June $2001 .{ }^{4}$ Of these, over $95000(2.3 \%)$ resulted in hospitalization. ${ }^{4}$

Much research into sports injuries has focused on younger populations or high school and college athletes. ${ }^{5-10}$ Additionally, sports and recreation related injuries are often thought anecdotally to be less severe than other types of unintentional injuries, and many studies describe injuries treated in emergency departments and outpatient settings. ${ }^{41-16}$ Research efforts have typically not focused on the more serious end of the spectrum of sports and recreation related injuries, such as those resulting in hospitalization. Therefore, we present a population based study of the estimated incidence and demographic patterns of sports and recreation related injuries resulting in hospitalization in Wisconsin in 2000.

\section{METHODS}

Data source and population

Data were obtained from the Wisconsin Bureau of Health Information (BHI) computerized database of hospital inpatient discharge data. This statewide database, maintained though a mandatory reporting system, includes demographic and diagnostic information and details of hospitalization for all patients admitted as inpatients to acute care non-federal hospitals in Wisconsin.

\section{Case definition}

We identified sports and recreation related injury cases resulting in inpatient hospitalization in Wisconsin in 2000 based on the mechanism of injury described by the International Classification of Diseases, Ninth Revision, Clinical Modification (ICD-9-CM) external cause of injury code (E code). Wisconsin law requires that any injury diagnosis documented during hospitalization be accompanied by an E code. To avoid double counting, hospitalizations transferred from other acute care facilities were excluded.

There is no single or universal E code used to designate a sports and recreation related external cause of injury; therefore we developed a classification scheme based on the methodology of Baker et $a l^{17}$ and Kraus and Conroy ${ }^{18}$ for estimating the incidence of sports and recreation related fatalities. We included only the proportion of injuries within each $\mathrm{E}$ code estimated to be sports and recreation related, unless the E code explicitly stated a sports related external cause of injury. A proportion for each E code, with low and high limits around it, was determined based on previously published epidemiologic studies of injury and on other authors' estimations. ${ }^{17}{ }^{18}$

Abbreviations: $\mathrm{BHI}$, Bureau of Health Information; ICD-9-CM, International Classification of Diseases, Ninth Revision, Clinical Modification; E code, External Cause of Injury code; BUGS, Bayesian inference Using Gibbs Sampling; Crl, credible interval. 
We assumed that fall related injuries to patients aged over 64 years were not sports and recreation related unless designated by an E code in which a sports and recreation related cause was specifically stated. This is the same approach used by Baker et al. ${ }^{17}$ Although this may underestimate the number of sports and recreation related fall injuries in adults over 64, it is unlikely that a large number of injuries would be missed, as $97 \%$ of all sports injuries occur in individuals from 5-49 years old. ${ }^{19}$

Code E 927 ("overexertion and strenuous movements") differs from other included $\mathrm{E}$ codes in that a relatively large number of hospitalizations receive this code but only a small percentage are likely to be sports and recreation related. To improve specificity, in the descriptive part of this study we excluded all cases in this category except those additionally designated by the code E849.4, indicating that the injury occurred in a "place for recreation and sport". Code E 849.4 is not consistently used for all sports injuries, however, and is not, by itself, a good measure of the frequency of sports and recreation related injuries. See table 1 for a summary of included circumstances of injury and the percent thought to be sports and recreation related within each circumstance.

\section{ANALYSIS \\ Estimated number of sports and recreation related injury hospitalizations}

Bayesian analysis with a Markov chain Monte Carlo approach (Bayesian inference Using Gibbs Sampling (BUGS) 1.4 software) was used to model the uncertainty in the measured number of injuries as well as that in the estimated proportion of injuries attributable to sports and recreation. For each category the number of injury hospita- lizations was assumed to be Poisson distributed with an unknown mean, mean ${ }_{i}$. Each mean $_{i}$ was given an uninformed, or highly diffuse, gamma prior with parameters $\alpha=0.1$ and $\lambda=0.002$. The proportions, $P_{i}$ of injuries related to sports and recreation were given logit-normal prior distributions. The parameters of these logit-normals were determined using the low, middle, and high values for the percent of injuries thought to be sports and recreation related within each circumstance of injury. Thus the priors for $P_{i}$ s included informed input whereas the priors for mean $_{i}$ were noninformative. Using Gibbs sampling to obtain samples from the posterior distributions of sportinj $j_{i}=$ mean $_{i} \times P_{i}$, we calculated a point estimate and $95 \%$ credible interval for each circumstance of injury and, by summing across categories in each post-data sample, for all sports and recreation related injuries combined. A credible interval is the Bayesian analogue of the confidence interval, but differs in that it enables direct probability statements based on the observed data and the prior distribution, in contrast to a confidence interval that describes the interval estimation for a parameter that would be expected from multiple repetitions of an experiment. ${ }^{20}$

\section{Injury rates}

To calculate the rate of sports and recreation related injuries within each circumstance of injury and overall, we used the mean number of injuries determined by the BUGS model as the numerator, and Wisconsin population statistics for 2000 as the denominator. For age and sex specific rates within each circumstance of injury, numerators were the observed number of injuries to the group of interest multiplied by the midpoint estimated percent of sports and recreation

Table 1 Included $\mathrm{E}$ code groups and estimates for the percent of injuries within each E code group related to sports and recreation*

\begin{tabular}{|c|c|c|c|c|}
\hline \multirow[b]{2}{*}{ ICD-9-CM E code group } & \multirow[b]{2}{*}{ Circumstance of injury } & \multicolumn{3}{|c|}{$\begin{array}{l}\text { Estimated percentage of cases } \\
\text { sports and recreation related }\end{array}$} \\
\hline & & Low (\%) & Mid (\%) & High (\%) \\
\hline $\begin{array}{l}810-819(0.5) ; 822-825(0.5) ; \\
826-829(0.2)\end{array}$ & Animal being ridden & 30 & 50 & 70 \\
\hline $830-838(0.0,0.1,0.3,0.5,0.9)$ & Boating & 75 & 95 & 99 \\
\hline 883 & Diving/jumping into water/swimming pool & 50 & 75 & 90 \\
\hline 910.2 & Drowning in other sport/recreation & 100 & 100 & 100 \\
\hline 910.1 & $\begin{array}{l}\text { Drowning in sport/rec with diving } \\
\text { equipment }\end{array}$ & 100 & 100 & 100 \\
\hline 910.8 & Drowning in swimming pool & 20 & 40 & 60 \\
\hline 884.1 & Fall from cliff & 10 & 50 & 90 \\
\hline 884.9 & Fall from one level to another ( $<65$ years) & 1 & 5 & 10 \\
\hline 884.0 & Fall from playground equipment & 100 & 100 & 100 \\
\hline 880.1 & Fall on or from curb ( $<65$ years) & 1 & 5 & 10 \\
\hline 886 & Fall on same level in sports & 100 & 100 & 100 \\
\hline 885 & $\begin{array}{l}\text { Fall same level from slipping/tripping } \\
\text { ( }<65 \text { years) }\end{array}$ & 1 & 5 & 10 \\
\hline 914 & Foreign body in eye & 10 & 20 & 30 \\
\hline 922 (excluding 922.3) & Hunting firearm injury & 10 & 20 & 30 \\
\hline 907 & Lightning & 1.5 & 25 & 50 \\
\hline 820 (excluding $0.2,0.3,0.4$ ) & Off-road snow vehicle & 70 & 75 & 95 \\
\hline 821 (excluding 0.4) & Off-road vehicle, excluding snow & 25 & 50 & 75 \\
\hline 888 & Other fall ( $<65$ years) & 1 & 5 & 10 \\
\hline 848 & Other vehicle not elsewhere classifiable† & 50 & 70 & 75 \\
\hline 927 & Overexertion/strenuous movements & 1 & 1.25 & 2.5 \\
\hline $840-844(0.7)$ & Parachuting & 25 & 50 & 75 \\
\hline $\begin{array}{l}810-819(0.6) ; 822-825(0.6) ; \\
826-829(0.1)\end{array}$ & Pedal cycle & 50 & 70 & 90 \\
\hline 847 & Ski chair lift/cable car & 50 & 90 & 100 \\
\hline 917 & Struck against or by object in sports & 100 & 100 & 100 \\
\hline $840-844(0.6)$ & Unpowered aircraft & 100 & 100 & 100 \\
\hline $830-838(0.4) ; 910.0$ & Waterskiing & 100 & 100 & 100 \\
\hline
\end{tabular}


related injuries within that circumstance of injury, and denominators were corresponding Wisconsin population statistics for 2000 (United States Census data).

Preliminary analyses performed in preparation for this study showed differences in sex and age distribution for $\mathrm{E}$ codes deemed to be highly sports and recreation related (75\% or more estimated to be related to sports or recreation) compared to other $\mathrm{E}$ codes, with males and individuals ages 5-34 years disproportionately represented in the more highly sports and recreation related E codes. Therefore, we performed additional analyses of age and sex separately for the highly sports and recreation related E codes.

We compared rates of hospitalization for sports and recreation related injury among residents of urban, intermediate, and rural counties. The ZIP code of residence for each individual was used to determine the injured party's county of residence. Counties were considered urban if they contained a city with a population of 50000 or greater, and intermediate if they were listed as metropolitan by the Wisconsin Department of Health and Family Services (2000) but did not contain a city of over 50 000. All other counties were considered rural.

\section{RESULTS}

The estimated mean number of sports and recreation related injuries resulting in hospitalization in Wisconsin in 2000 was 1714 (95\% credible interval (CrI) 1499 to 2022), a rate of 32.0 (95\% CrI 27.9 to 37.7) per 100000 population. Sports and recreation related injuries represented $3.5 \%$ of all unintentional injury hospitalizations. Table 2 shows the estimated mean number and rate of injuries with $95 \%$ credible intervals for each circumstance of injury and for sports and recreation related injuries overall. The mean number of estimated sports related injuries in each circumstance may not exactly equal the product of observed number of injuries and the midpoint of estimated proportion from table 1 . This is because the Bayesian model takes into account the uncertainty in the estimates of the proportions.

The most common circumstance of injury was being struck by or against an object in sports (6.4 hospitalizations per 100000 population). Motor or non-motor vehicle recreation (pedal cycles, snowmobiles, and off-road vehicles) accounted for the three next most frequent causes of sports and recreation related injury hospitalization. Rates of hospitalization for injuries related to "extreme" sports such as rock climbing (fall from cliff, 0.1 per 100000$)$, parachuting $(0.1$ per 100000$)$, scuba diving (0.0 per 100000$)$, and gliding (unpowered aircraft, 0.1 per 100 000) were low in Wisconsin.

\section{AGE AND SEX}

The highest per population rate of sports and recreation related injury resulting in hospitalization was seen in 10-19 year olds, and the lowest in adults 65 years and above (table 3). In 5-19 year olds, sports and recreation related injuries accounted for $15-20 \%$ of all unintentional injury hospitalizations. In absolute terms, more pedal cycle and off-road vehicle related injury hospitalizations occurred in 10-19 year olds than in any other age group. In adults 65 years of age and older, relatively low rates were seen for most sports and recreation related circumstances of injury; however the rate of pedal cycle injuries resulting in hospitalization in this age group was higher than for all other circumstances of injury combined, and was similar to or higher than rates of pedal cycle related injuries for all other age groups except 5-19 year olds.

In separate analyses of the $\mathrm{E}$ codes highly related to sports and recreation, males had higher rates of hospitalization for all ages, except over 64 years old (fig 1). The highest rate of hospitalization for males was in 10-19 year olds, with a rate
Table 2 Number and rate of sports and recreation related injuries resulting in hospitalization, Wisconsin 2000

\begin{tabular}{|c|c|c|c|}
\hline \multirow[b]{2}{*}{$\begin{array}{l}\text { Circumstance of } \\
\text { injury }\end{array}$} & \multirow[b]{2}{*}{$\begin{array}{l}\text { Total no } \\
\text { in } \mathrm{E} \text { code } \\
\text { group }\end{array}$} & \multicolumn{2}{|c|}{ Sports and recreation related injuries } \\
\hline & & $\begin{array}{l}\text { Mean number of } \\
\text { injuries }(95 \% \\
\text { credible interval)* }\end{array}$ & $\begin{array}{l}\text { Rate per } 100000 \\
\text { population ( } 95 \% \\
\text { credible interval) }\end{array}$ \\
\hline $\begin{array}{l}\text { Animal being } \\
\text { ridden }\end{array}$ & 146 & 73 (43 to 106$)$ & $1.4(0.8$ to 2$)$ \\
\hline Boating & 42 & 39 (27 to 53$)$ & $0.7(0.5$ to 1$)$ \\
\hline $\begin{array}{l}\text { Diving/jumping into } \\
\text { water/swimming } \\
\text { pool }\end{array}$ & 25 & $18(10$ to 28$)$ & $0.3(0.2$ to 0.5$)$ \\
\hline $\begin{array}{l}\text { Drowning in other } \\
\text { sport/recreation }\end{array}$ & 9 & $9(4$ to 16$)$ & $0.2(0.1$ to 0.3$)$ \\
\hline $\begin{array}{l}\text { Drowning in sport/ } \\
\text { recreation with } \\
\text { diving equipment }\end{array}$ & 0 & $0(0$ to 1$)$ & $0.0(0$ to 0$)$ \\
\hline $\begin{array}{l}\text { Drowning in } \\
\text { swimming pool }\end{array}$ & 26 & 11 (5 to 19) & $0.2(0.1$ to 0.4$)$ \\
\hline Fall from cliff & 11 & $6(1$ to 13$)$ & $0.1 \quad(0$ to 0.2$)$ \\
\hline $\begin{array}{l}\text { Fall from one level } \\
\text { to another }(<65 \\
\text { years) }\end{array}$ & 607 & $40(6$ to 131$)$ & $0.7(0.1$ to 2.4$)$ \\
\hline $\begin{array}{l}\text { Fall from } \\
\text { playground } \\
\text { equipment }\end{array}$ & 122 & 122 (101 to 144$)$ & 2.3 (1.9 to 2.7$)$ \\
\hline Fall in sports & 62 & $62(48$ to 78$)$ & $1.2(0.9$ to 1.5$)$ \\
\hline $\begin{array}{l}\text { Fall on or from curb } \\
(<65 \text { years })\end{array}$ & 21 & $1(0$ to 5$)$ & $0.0(0$ to 0.1$)$ \\
\hline $\begin{array}{l}\text { Fall same level from } \\
\text { slip/trip (<65 } \\
\text { years) }\end{array}$ & $n 1215$ & 80 (12 to 262$)$ & 1.5 (0.2 to 4.9$)$ \\
\hline Foreign body in eye & 23 & 5 (2 to 9$)$ & $0.1 \quad(0$ to 0.2$)$ \\
\hline $\begin{array}{l}\text { Hunting firearm } \\
\text { injury }\end{array}$ & 98 & $20(9$ to 36$)$ & $0.4(0.2$ to 0.7$)$ \\
\hline Lightning & 5 & $2(0$ to 6$)$ & $0.0(0$ to 0.1$)$ \\
\hline $\begin{array}{l}\text { Off-road snow } \\
\text { vehicle }\end{array}$ & 262 & 196 (170 to 224) & 3.7 (3.2 to 4.2$)$ \\
\hline $\begin{array}{l}\text { Off-road vehicle, } \\
\text { excluding snow }\end{array}$ & 284 & 142 (70 to 216$)$ & $2.6(1.3$ to 4$)$ \\
\hline $\begin{array}{l}\text { Other fall }(<65 \\
\text { years) }\end{array}$ & 1557 & 103 (16 to 335$)$ & $1.9(0.3$ to 6.2$)$ \\
\hline $\begin{array}{l}\text { Overexertion/ } \\
\text { strenuous } \\
\text { movements }\end{array}$ & 1408 & 14 (12 to 17$)$ & $0.3(0.2$ to 0.3$)$ \\
\hline Parachuting & 10 & $5(2$ to 10$)$ & $0.1 \quad(0$ to 0.2$)$ \\
\hline Pedal cycle & 474 & 328 (233 to 408$)$ & $6.1 \quad(4.3$ to 7.6$)$ \\
\hline $\begin{array}{l}\text { Skateboard/ } \\
\text { scooter/ice yacht/ } \\
\text { other vehicle }\end{array}$ & 113 & 78 (54 to 103) & $1.5(1$ to 1.9$)$ \\
\hline Ski lift/cable car & 2 & $2(0$ to 5$)$ & $0.0(0$ to 0.1$)$ \\
\hline $\begin{array}{l}\text { Struck against or by } \\
\text { object in sports }\end{array}$ & y 341 & 341 (305 to 377) & $6.4(5.7$ to 7$)$ \\
\hline Unpowered aircraft & 7 & 7 (3 to 13) & $0.1 \quad(0.1$ to 0.2$)$ \\
\hline Waterskiing & 11 & 11 (6 to 18) & $0.2(0.1$ to 0.3$)$ \\
\hline $\begin{array}{l}\text { All sports and } \\
\text { recreation related } \\
\text { injuries }\end{array}$ & & $\begin{array}{c}1714 \text { (1499 to } \\
2022)\end{array}$ & $\begin{array}{ll}32.0 & (27.9 \text { to } \\
37.7)\end{array}$ \\
\hline
\end{tabular}

of 65 sports and recreation related injury hospitalizations per 100000 population. The peak for females was in 5-9 year olds with a rate of 20.5 per 100000 . Overall males had roughly a four times higher risk of experiencing a sports and recreation related injury resulting in hospitalization compared with females ( $\mathrm{RR}=4.2$, 95\% CI 3.6 to 5.0 ).

\section{COUNTY OF RESIDENCE OF INJURED}

Rural counties exhibited the highest rate of hospitalization for sports and recreation related injuries overall (see http:// www.injuryprevention.com/supplemental for table 4). Intermediate counties had the lowest overall rate $(R R=0.69,95 \%$ CI 0.57 to 0.83 compared with rural), whereas the overall rate for urban counties was intermediate $(\mathrm{RR}=0.86,95 \%$ CI 0.77 
Table 3 Rates per 100000 of sports and recreation related injuries resulting in hospitalization by age, Wisconsin 2000

\begin{tabular}{|c|c|c|c|c|c|c|c|c|c|c|c|c|c|c|c|}
\hline \multirow[b]{2}{*}{ Circumstance of injury } & \multicolumn{2}{|c|}{$<5$ years } & \multicolumn{2}{|c|}{$5-9$ years } & \multicolumn{2}{|c|}{$\begin{array}{l}10-19 \\
\text { years }\end{array}$} & \multicolumn{2}{|c|}{$\begin{array}{l}20-34 \\
\text { years }\end{array}$} & \multicolumn{2}{|c|}{$35-54$ years } & \multicolumn{2}{|c|}{$\begin{array}{l}55-64 \\
\text { years }\end{array}$} & \multicolumn{3}{|c|}{$65+$ years } \\
\hline & $\mathbf{n}$ & Rate $^{*}$ & $\mathbf{n}$ & Rate & $\mathbf{n}$ & Rate & $\mathbf{n}$ & Rate & n & Rate & $\mathbf{n}$ & Rate & $\mathbf{n}$ & Rat & \\
\hline Animal being ridden & 1 & 0.1 & 3 & 0.7 & 11 & 1.3 & 12 & 1.1 & 37 & 2.3 & 7 & 1.4 & 5 & 5 & 0.6 \\
\hline Boating & 0 & 0.0 & 0 & 0.0 & 4 & 0.5 & 11 & 1.1 & 18 & 1.1 & 2 & 0.4 & 5 & 5 & 0.7 \\
\hline Dive/jump into water/swimming pool & 0 & 0.0 & 0 & 0.0 & 6 & 0.7 & 7 & 0.6 & 6 & 0.4 & 0 & 0.0 & 0 & 0 & 0.0 \\
\hline Drowning in sport/recreation & 1 & 0.3 & 1 & 0.3 & 1 & 0.1 & 2 & 0.2 & 2 & 0.1 & 2 & 0.4 & & 0.0 & 0.0 \\
\hline Drowning in swimming pool & 5 & 1.4 & 1 & 0.3 & 2 & 0.2 & 1 & 0.1 & 1 & 0.1 & 0 & 0.0 & & 0.4 & 0.1 \\
\hline Fall from cliff & 0 & 0.0 & 0 & 0.0 & 3 & 0.3 & 3 & 0.2 & 0 & 0.0 & 0 & 0.0 & & 0.5 & 0.1 \\
\hline Fall from one level to another ( $<65$ years) & 3 & 0.8 & 3 & 0.7 & 5 & 0.6 & 5 & 0.4 & 12 & 0.7 & 4 & 0.8 & $\dagger$ & $\dagger$ & $\dagger$ \\
\hline Fall from playground equipment & 26 & 7.6 & 75 & 19.8 & 14 & 1.7 & 2 & 0.2 & 3 & 0.2 & 1 & 0.2 & 1 & 1 & 0.1 \\
\hline Fall in sports & 0 & 0.0 & 1 & 0.3 & 40 & 4.9 & 15 & 1.4 & 4 & 0.2 & 2 & 0.4 & 0 & 0 & 0.0 \\
\hline Fall on or from curb ( $<65$ years) & 0 & 0.0 & 0 & 0.0 & 0 & 0.0 & 0 & 0.0 & 1 & 0.0 & 0 & 0.0 & $\dagger$ & $\dagger$ & $\dagger$ \\
\hline Fall same level from slip/trip ( $<65$ years) & 1 & 0.3 & 1 & 0.3 & 4 & 0.5 & 8 & 0.8 & 26 & 1.6 & 20 & 4.3 & $\dagger$ & $\dagger$ & $\dagger$ \\
\hline Foreign body in eye & 0 & 0.0 & 0 & 0.0 & 0 & 0.0 & 2 & 0.2 & 1 & 0.0 & 0 & 0.0 & 1 & 1 & 0.2 \\
\hline Hunting firearm injury & 0 & 0.1 & 0 & 0.1 & 6 & 0.7 & 6 & 0.6 & 5 & 0.3 & 1 & 0.1 & 1 & 1 & 0.1 \\
\hline Lightning & 0 & 0.0 & 0 & 0.0 & 0 & 0.0 & 1 & 0.0 & 1 & 0.0 & 0 & 0.0 & 0 & 0 & 0.0 \\
\hline Off-road snow vehicle & 0 & 0.0 & 2 & 0.4 & 38 & 4.6 & 85 & 8.0 & 61 & 3.8 & 10 & 2.1 & 2 & 2 & 0.3 \\
\hline Off-road vehicle, excluding snow & 3 & 0.7 & 7 & 1.7 & 44 & 5.4 & 39 & 3.7 & 34 & 2.1 & 8 & 1.6 & 9 & 9 & 1.3 \\
\hline Other fall ( $<65$ years) & 2 & 0.5 & 2 & 0.4 & 4 & 0.5 & 10 & 0.9 & 35 & 2.1 & 26 & 5.7 & $\dagger$ & $\dagger$ & $\dagger$ \\
\hline Overexertion/strenuous movements & $\overline{0}$ & 0.0 & 0 & 0.0 & 9 & 1.1 & 4 & 0.4 & 5 & 0.3 & 0 & 0.0 & 0 & 0 & 0.0 \\
\hline Parachuting & 0 & 0.0 & 0 & 0.0 & 0 & 0.0 & 3 & 0.2 & 3 & 0.2 & 0 & 0.0 & 0 & 0 & 0.0 \\
\hline Pedal cycle & 6 & 1.8 & 53 & 13.8 & 113 & 13.9 & 33 & 3.1 & 71 & 4.4 & 25 & 5.5 & 31 & & 4.4 \\
\hline Skateboard/scooter/ice yacht/other vehicle & 8 & 2.2 & 8 & 2.2 & 28 & 3.5 & 18 & 1.6 & 11 & 0.7 & 4 & 0.8 & 4 & 4 & 0.5 \\
\hline Ski lift/cable car & 0 & 0.0 & 1 & 0.2 & 1 & 0.1 & 0 & 0.0 & 0 & 0.0 & 0 & 0.0 & 0 & 0 & 0.0 \\
\hline Struck against or by object in sports & 3 & 0.9 & 11 & 2.9 & 196 & 24.2 & 85 & 8.0 & 42 & 2.6 & 3 & 0.7 & 1 & 1 & 0.1 \\
\hline Unpowered aircraft & 0 & 0.0 & 0 & 0.0 & 0 & 0.0 & 2 & 0.2 & 3 & 0.2 & 1 & 0.2 & 1 & 1 & 0.1 \\
\hline Waterskiing & 0 & 0.0 & 0 & 0.0 & 2 & 0.2 & 2 & 0.2 & 7 & 0.4 & 0 & 0.0 & 0 & 0 & 0.0 \\
\hline All sports/recreation injuries & 58 & 17 & 167 & 44 & 529 & 65 & 354 & 33 & 387 & 24 & 113 & 25 & 61 & & 9 \\
\hline Non sports/recreation injuries & 1353 & 395 & 695 & 183 & 2594 & 320 & 4385 & 412 & 9084 & 565 & 4448 & 972 & 24601 & 1350 & \\
\hline All unintentional injuries & 1410 & 412 & 862 & 227 & 3123 & 385 & 4739 & 446 & 9471 & 589 & 4561 & 996 & 24662 & 2351 & \\
\hline
\end{tabular}

For sports/recreation related circumstances of injury, $\mathrm{n}$ includes only the number of cases within each discharge category estimated to be sports/recreation related.

Columns may not add to totals due to rounding.

*Per 100000 population

†Age $>64$ excluded from analysis for these codes.

to 0.96 compared with rural). Rates for injuries related to being struck by or against an object in sports were significantly higher in both rural and urban counties compared with intermediate. Pedal cycle related injury hospitalizations were significantly higher in residents of urban compared with intermediate counties but did not differ significantly between urban and rural or rural and intermediate counties.

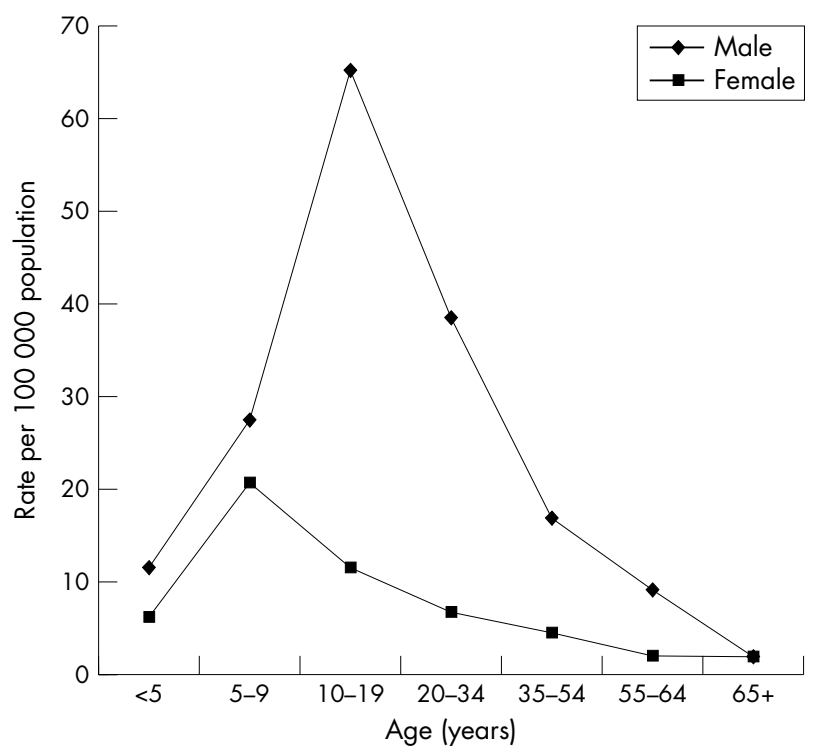

Figure 1 Rate of hospitalization for selected sports and recreation related injuries* in Wisconsin by age and sex, 2000. *Includes only injuries for $\mathrm{E}$ codes in which $75 \%$ or greater of cases are related to sports and recreation (see text for details).

\section{DISCUSSION}

This is among the first population based studies to estimate the incidence of and describe patterns of hospitalization for sports and recreation related injuries. An estimated 1714 hospitalizations for sports and recreation related injuries occurred in Wisconsin in 2000, accounting for 3.5\% of unintentional injury hospitalizations. We found that sports and recreation related injuries made up a smaller proportion of unintentional injury hospitalizations than that reported in studies restricted to children and adolescents, ${ }^{5921}$ consistent with our findings of higher sports and recreation related injury rates in youth. Sports and recreation related injuries have been reported previously to account for $4.1 \%$ of all-ages injury deaths in the US. ${ }^{22}$

Three of the four most common types of sports and recreation related injuries resulting in hospitalization in Wisconsin involved motor or non-motor vehicles (all terrain vehicles, snowmobiles, and pedal cycles), highlighting the ongoing issue of statewide safety education and helmet use policies for these activities. Wisconsin law mandates that, on public land, all off-road vehicle operators under 18 years of age use protective headgear, and riders under 16 years must complete safety education unless accompanied by a person at least 18 years of age. Ten to 19 year olds, however, had the highest number of off-road vehicle injuries resulting in hospitalization in Wisconsin, highlighting the need for additional injury prevention strategies. On 1 January 2001, a policy requiring all snowmobile operators in Wisconsin born after 1 January 1985 to complete safety education was implemented. Findings of the present study can serve as a useful baseline for monitoring the impact of this policy change and other safety interventions.

Consistent with several other studies reporting per population injury rates by age and sex, ${ }^{56923-26}$ we found that 
teens had the highest per population rates of sports and recreation related injury resulting in hospitalization, and males had higher rates than females for all ages except over 64 years old. It is not clear whether the observed differences are due to behavioral factors, differences in exposure to risk (for example, higher sports and recreational activity participation rates among teens and males), or some combination of these and other factors. In a study examining sex differences in sports injury rates per participant across comparable sports, Powell and Barber-Foss reported that females actually have similar rates of sports injuries to males (and higher rates for certain sports such as soccer and softball). ${ }^{27}$ Garrick and Requa also found a higher per participant rate of injuries for females participating in softball compared with males in baseball, and similar injury rates across sexes for other activities with both male and female participants (basketball, track and field, cross country, swimming, tennis, and gym). ${ }^{10}$ However, for all sports combined, the per participant rate for males was twice that for females, primarily because the highest per participant injury rates occurred in football and wrestling-sports in which there were no female participants in that particular study. None of these earlier studies reported age and sex patterns of injuries resulting in hospitalization specifically, however. Further research is needed to determine whether the higher rates of sports and recreation related injury resulting in hospitalization among males and teens are caused by behavioral factors, differing exposure levels, or other factors.

Although rates of sports and recreation related injury resulting in hospitalization in Wisconsin were generally low for people 65 years of age and older, the rate of pedal cycle related injuries resulting in hospitalization in this age group was as high as that of 20-34 and 35-54 year olds. An analysis of data from the Consumer Product Safety Commission's National Electronic Injury Surveillance System (NEISS) reported that in 1996 there were 11000 bicycle related injury visits to emergency departments in the US by people 65 years of age or older. ${ }^{28}$ This represented a $75 \%$ increase in the number of bicycle related injury emergency department visits compared with 1990, although the 65 and over population grew by just over $8 \%$ in the same time period. ${ }^{28}$ Higher participation in bicycling by older Americans may be responsible for the increasing injury rate, although our findings may also reflect that older cyclists are at increased risk of serious injury compared with younger cyclists. Methodologic limitations prevented comprehensive injury surveillance in people 65 years of age and older, however, and additional research is needed to characterize better sports and recreation related injury risk among this age group.

Residents of rural counties had higher rates of sports and recreation related injury resulting in hospitalization than residents of urban or intermediate counties, both overall and for many circumstances of injury individually. Different patterns of participation may in part be responsible for this. Other possible explanations include different criteria for hospital admission in rural compared with urban hospitals, and less injury prevention education and immediate care of injuries related to limited sporting event "sideline" or onsite care in rural communities ${ }^{29}$ (personal communication, Darin Rutherford)

There are several limitations to this study. Because it was conducted in a single state during a specific year, it cannot be directly generalized to other time periods or other states or countries where weather, pattern of recreational activities, or medical care practices may vary. Inherent in any analysis of hospital discharge databases, the questions that can be answered are limited by data collected previously for administrative purposes. We cannot examine patterns of injury within specific team sports, since ICD-9-CM codes do not include information on sports team participation. Nor can we fully evaluate injuries by means of a tool such as Haddon's matrix ${ }^{30}$ because information on key factors that may influence injury outcomes (for example, use of protective equipment, alcohol use) is not available in the database.

Another difficulty in this study arose because the ICD-9CM coding system does not assign a specific E code to injuries designating a sports and recreation related cause of injury. The need to estimate the proportion of each E code attributable to sports and recreation related injuries adds an additional source of uncertainty to our estimate of the incidence of hospitalizations for sports and recreation related injuries and to our description of the characteristics of individuals hospitalized with these injuries. To partially address this uncertainty, we modeled the incidence of sports and recreation related injuries using Bayesian analysis and employed a distribution of values over a range of possibilities instead of a single value for the unknown proportion.

Lack of exposure information is an important limitation of this study. As the denominators for this study are from population statistics, our rate estimates do not provide information about relative risks per participant-time for different activities, nor can we separate the effect of higher participation rates from other factors which potentially increase risk among groups with higher sports and recreation related injury hospitalization rates. In order to tailor prevention strategies to groups at high risk for sports and recreational injuries without simply discouraging participation, participation rates and exposure data must be collected. ${ }^{31}$

A limitation to using population denominators is that some out-of-state residents are hospitalized in Wisconsin hospitals. Conversely, some Wisconsin residents, particularly those in counties bordering adjacent states, may be hospitalized outside of Wisconsin. A special study by the Wisconsin Department of Health and Family Services indicates that the number of patients crossing Wisconsin state lines for hospitalization in either direction is relatively small and similar in both directions. That study found that $4 \%$ of discharges from Wisconsin hospitals were of residents of other states while the number of Wisconsin residents admitted to non-Wisconsin hospitals was equal to 5\% of the Wisconsin hospital discharges. ${ }^{32}{ }^{33}$ Although the former could have been excluded from the numerator for these analyses, the latter could not have been added because those data are not available. Therefore our approach of calculating rates using a numerator of all discharges of Wisconsin and non-Wisconsin residents and a denominator of Wisconsin residents should provide more accurate rates than simply excluding discharges to non-Wisconsin residents from the numerator.

Other studies using E codes from hospitalization data to analyze injury patterns have encountered problems with incompleteness of data, which results when hospitals do not provide E codes for a proportion of injured patients. ${ }^{34} 35$ However, E code data in Wisconsin is virtually complete, with over $99 \%$ of injury diagnoses accompanied by an E code diagnosis. ${ }^{36}$ The accuracy of $\mathrm{E}$ code diagnoses has not been systematically evaluated, however, and the extent to which differences occur between institutions or individual coders is not known.

The results of this study may be useful in generating hypotheses regarding the patterns and causes of serious sports and recreation related injuries and in setting priority areas for future investigation. The present study offers limited capacity to describe patterns of sports and recreation related injury in older adults, and this is an important and 


\section{Key points}

- This is among the first population based studies to examine hospitalizations for sports and recreation related injuries.

- The rate of injuries resulting in hospitalization is highest among youth, males, and those living in rural areas.

- Information on participation rates and exposure time is needed to compare risks of sports and recreation related injury between activities and to help target prevention strategies for high risk groups.

- Future studies are needed to help clarify the relation between physical activity level and injury, and to guide development of physical activity recommendations for achieving the many benefits of lifelong exercise while minimizing the risk of injuries.

growing area for further research. Additionally, some authors have questioned whether the benefits of increasing physical activity, as called for by federal and private groups to prevent chronic disease, ${ }^{37} 38$ might be counterbalanced or even outweighed by an increased incidence of sports and recreation related injuries in those who are active. ${ }^{39} 40$ Further research is needed to help clarify the relation between physical activity level and injury and other potential adverse outcomes, such as exercise precipitated heart attacks. Such research would guide development of physical activity recommendations for achieving the many benefits of lifelong exercise while minimizing the risk of injuries or other adverse effects.

\section{Authors' affiliations}

R L Dempsey, P M Layde, C E Guse, Injury Research Center and the Department of Family and Community Medicine, Medical College of Wisconsin, Milwaukee, WI, USA

P W Laud, Injury Research Center, Health Policy Institute and the Department of Biostatistics, Medical College of Wisconsin, Milwaukee, WI, USA

S W Hargarten, Injury Research Center and the Department of Emergency Medicine, Medical College of Wisconsin, Milwaukee, WI, USA

Supported in part by US Centers for Disease Control and Prevention Grant PHS CDC R49 CCR519614 and by US Department of Health and Human Services National Research Service Award Grant 1T32 PE 10030-03

The authors report no competing interests.

\section{REFERENCES}

1 Tremblay MS, Willms JD. Is the Canadian childhood obesity epidemic related to physical inactivity? Int J Obes Relat Metab Disord 2003;27:1100-5.

2 Donnelly JE, Hill JO, Jacobsen DJ, et al. Effects of a 16-month randomized controlled exercise trial on body weight and composition in young, overweight men and women: the Midwest Exercise Trial. Arch Intern Med 2003:163:1343-50.

3 Steinbeck KS. The importance of physical activity in the prevention of overweight and obesity in childhood: a review and an opinion. Obes Rev 2001;2:117-30.

4 Centers for Disease Control and Prevention. Nonfatal sports- and recreationrelated injuries treated in emergency departments - United States, July 2000June 2001. Morb Mortal Wkly Rep 2002;51:736-40.

5 Gallagher SS, Kinison K, Guyer B, et al. The incidence of injuries among 87,000 Massachusetts children and adolescents: results of the 1980-81 Statewide Childhood Injury Prevention Program Surveillance System. Am J Public Health 1984;74:1340-7.
6 Bienefeld M, Pickett W, Carr PA, et al. A descriptive study of childhood injuries in Kingston, Ontario, using data from a computerized injury surveillance system. Chronic Dis Can 1996;17:21-7.

7 Bijur PE, Trumble A, Harel Y, et al. Sports and recreation injuries in US children and adolescents. Arch Pediatr Adolesc Med 1995; 149:1009-16.

8 Rice SG, Schlotfeldt JD, Foley WE. The Athletic Health Care and Training Program. A comprehensive approach to the prevention and management of athletic injuries in high schools. West J Med 1985;142:352-7.

9 Cheng TL, Fields CB, Brenner RA, et al. Sports injuries: an important cause of morbidity in urban youth. Pediatrics 2000;105:1-6.

10 Garrick JG, Requa RK. Injuries in high school sports. Pediatrics 1978;61:465-9.

11 Bedford PJ, Macauley DC. Attendances at a casualty department for sport related injuries. Br J Sports Med 1984;18:116-21.

12 Burke P, Buckley N, McShane D, et al. Sports injuries and the casualty department. Ir Med J 1983;76:127-9

13 Burt CW, Overpeck MD. Emergency visits for sports-related injuries. Ann Emerg Med 2001;37:301-8.

14 Branche CM, Conn JM, Annest JL. Personal watercraft-related injuries. JAMA 1997;278:663-5.

15 Smith GS. Injuries to children in the United States related to trampolines, 1990-1995: A national epidemic. Pediatrics 1998;101:406-12.

16 Centers for Disease Control and Prevention. Injuries associated with horseback riding-United States, 1987 and 1988. Morb Mortal Wkly Rep 1990;39:329-32

17 Baker S, O'Neill B, Ginsburg M, et al. Sports and Recreation. In: The injury fact book. New York: Oxford University Press, 1992:89-99.

18 Kraus JF, Conroy C. Mortality and morbidity from injuries in sports and recreation. Annu Rev Public Health 1984:5:163-92.

19 Dekker R, Kingma J, Groothoff JW, et al. Measurement of severity of sports injuries: an epidemiological study. Clin Rehabil 2000;14:651-6.

20 Carlin BP, Lovis TA. Bayesian Inference. In: Bayes and empirical Bayes methods for data analysis, 2nd edn. Boca Raton: Chapman \& Hall/CRC 2000:32-38.

21 Tursz A, Crost M. Sports-related injuries in children A study of their characteristics, frequency, and severity, with comparison to other types of accidental injuries. Am J Sports Med 1986;14:294-9.

22 Conn JM, Annest JL, Gilchrist J. Sports and recreation related injury episodes in the US population, 1997-99. Inj Prev 2003;9:117-23.

23 Rivara FP, Calonge N, Thompson RS. Population-based study of unintentional injury incidence and impact during childhood. Am J Public Health 1989:79:990-4.

24 Rivara FP, Bergman AB, LoGerfo JP, et al. Epidemiology of childhood injuries. II. Sex differences in injury rates. Am J Dis Child 1982;136:502-6.

25 Zaricznyj B, Shattuck LM, Mast TA, et al. Sports-related injuries in schoolaged children. Am J Sports Med 1980;8:318-24.

26 King MA, Pickett W, King AJ. Injury in Canadian youth: A secondary analysis of the 1993-94 Health Behaviour in School-Aged Children survey. Can J Public Health 1998;89:397-401

27 Powell J, Barber-Foss K. Sex-related injury patterns among selected high school sports. Am J Sports Med 2000;28:385-91.

28 Rutherford GW, Schroeder TJ. Sports-related injuries to persons 65 years of age and older. Washington, D.C. : Consumer Product Safety Commission April 1998, Available at www.cpsc.gov/cpscpub/pubs/grand/aging/ injury65.pdf (accessed 31 January 2005).

29 Rutherford DS, Niedfeldt MW, Young CC. Medical coverage of high school football in Wisconsin in 1997. Clin J Sport Med 1999;9:209-15.

30 Haddon W Jr. A logical framework for categorizing highway safety phenomena and activity. J Trauma 1972;12:193-207.

31 Department of Health and Family Services, Division of Health, Center for Health Statistics. Market Share Analyses: Wisconsin 1986, Volume 1: Hospital Commitment Indices and Population Shares, June 1987.

32 Department of Health and Family Services, Division of Health, Center for Health Statistics. Market Share Analyses: Wisconsin 1986, Volume 2: Hospitals' Shares of ZIP code Areas, June 1987

33 de Loes M. Exposure data. Why are they needed? Sports Med 1997;24:172-5.

34 Marganitt B, MacKenzie EJ, Smith GS, et al. Coding external causes of injury (E-Codes) in Maryland Hospital Discharges 1979-88: A statewide study to explore the uncoded population. Am J Public Health 1990;10:1463-6.

35 Guyer B, Berenholz G, Gallagher SS. Injury surveillance using hospital discharge abstracts coded by external cause of injury (E code). J Trauma 1990;30:470-3.

36 Tavris DR, Kuhn EM, Layde PM. Hospitalizations for vehicle associated injuries in Wisconsin. WMJ 1999:98:34-9.

37 Pate PR, Pratt M, Blair S, et al. Physical activity and public health-A recommendation from the Centers for Disease Control and Prevention and the American College of Sports Medicine. JAMA 1995;273:402-7.

38 US Department of Health and Human Services, Centers for Disease Control and Prevention, National Center for Chronic Disease Prevention and Health Promotion. Physical Activity and Health: A Report of the Surgeon General. Atlanta, GA: Centers for Disease Control and Prevention, 1996.

39 Shephard RJ. Can we afford to exercise, given current injury rates? Inj Prev 2003;9:99-100.

40 Marshall SW, Guskiewicz KM. Sports and recreational injury: The hidden cost of a healthy lifestyle. Inj Prev 2003;9:100-2. 